\section{The differential effects of nitrazepam on}

\section{certain inhibitory and excitatory behaviors*}

\author{
ROBERT J. DOUGLAS and DAVID W. SCOTT \\ The University of Washington, Seattle, Wash. 98105
}

Nitrazepam, mixed with food, was orally administered to rats in doses of 0 , 10 , and $50 \mathrm{mg} / \mathrm{kg}$. Both doses, but especially the higher one, had obvious arousal-reducing effects in most Ss. Paradoxically, however, the 50-mg dose produced apparent "rage" behavior in several rats while seeming to "tranquilize" or depress the others. At the higher dose, there also was a marked depression in locomotor, postural, or righting behavior. Despite these obvious overall effects, neither dose had any reliable effect on spontaneous alternation, a response highly related to hippocampal damage or malfunction. Our results are at least consistent with the idea that the drug alters the function of the amygdala, but they are decidedly in opposition to suggestions in the literature that nitrazepam either inhibits or enhances the function of the hippocampus.

Nitrazepam, one of the new class of drugs known as benzodiazepines, is believed by many investigators to especially affect the limbic system (e.g., Morillo, 1962; Schallek, Zabransky, \& Kuehn, 1964; Schallek, Thomas, Kuehn, \& Zabransky, 1965). One might suspect this possibility purely on the basis of the general anticonvulsant properties of these compounds and their "taming" effect on animals (Randall \& Schallek, 1968). In addition, however, it was concluded from a study of amygdaloid stimulation and recording in the hippocampus that nitrazepam might simultaneously inhibit the amygdala and facilitate the hippocampus (Morillo, 1962). An opposite conclusion regarding the effects of the drug on hippocampal function might be drawn from the finding of Steiner \& Hummel (1968) that nitrazepam blocks the reception of visual input by the hippocampus.

None of these studies, however, gets directly at the problem of whether the contribution of the hippocampus to behavior is enhanced, depressed, or unaffected by the drug. Such a question is more directly approached by administering the drug and then testing the Ss on problems or responses which are highly dependent upon the integrity of the hippocampus.

There is no known behavior more sensitive to hippocampal lesions than the phenomenon of spontaneous alternation. As measured in the rat, spontaneous alternation refers to the powerful tendency of the rat to enter opposite alleys of a T-maze when given two consecutive unrewarded trials. A

*This research was supported in part by Grant MH 18760-01 from NIMH to the senior author. We are grateful to senior author. We are grateful to us a free supply of Mogadon ${ }^{(9)}$ and relevant information. consensus of the literature and our own extensive experience reveals that the normal rat generally alternates about $85 \%$ of the time or that $85 \%$ of a group of rats will alternate on any one test of the phenomenon. In contrast, large hippocampal lesions reduce this rate to somewhere near a chance $50 \%$ (Roberts, Dember, \& Brodwick, 1962; Douglas \& Isaacson, 1964). A similar loss occurs after lesions of the closely related septal region (Douglas \& Raphelson, 1966), but alternation is apparently completely unaffected by a wide variety of nonhippocampal-septal lesions, including amygdala, neocortex (various locations including frontal), or cingulate gyrus (Douglas, Kowal, \& Clark, 1968). Furthermore, the total absence of alternation following large hippocampal lesions occurs whether the lesion is made in one stage or two, in very young rats or in adults (Douglas \& Peterson, 1969). Thus, we reasoned that if nitrazepam had an effect on hippocampal function, then it might well show up in terms of changes in the alternation tendency. If the hippocampus were inactivated, then spontaneous alternation should be greatly reduced or abolished. A might manifest itself as an increase in the alternation rate to levels above the typical $85 \%$. Since the drug nitrazepam (Mogadon ${ }^{\circledR}$ ) is highly unstable in an aqueous solution, and since humans are typically given the drug orally, it was decided that an oral administration would be most appropriate. Two different doses were employed and the experiment halted when it became clear that the high dose produced grossly observable changes in either emotional behavior or locomotor reflexes in nearly all animals.

\section{SUBJECTS}

The Ss were eight 90-day-old female facilitation of hippocampal function hooded rats from the population bred in the Psychology Vivarium, University of Washington. An additional two Ss became resistant to maze running before the experiment could be completed and their data, though much like that of the others, is not included. Half were assigned randomly to Group 1 and the remainder to Group 2. Each $S$ was individually housed with continuous access to water.

\section{APPARATUS}

A standard T-maze was used with its main alley 16 in. long and its side alleys $18 \mathrm{in.}$ in length. The alleys were $5 \frac{1}{2}$ in. high and $4 \frac{1}{2}$ in. wide. A guillotine door was used between the startbox and the main alley and also between the choice point and each side alley. The maze was surrounded by brown craft paper, and the only illumination was provided by a hooded $15-\mathrm{W}$ light suspended above the choice point.

\section{PROCEDURE}

An alternation test consisted of two trials. For the first trial, $\mathrm{S}$ was placed in the startbox and the door to the main alley was raised. When $S$ entered a side alley, the door was lowered and the rat was confined there for $30 \mathrm{sec}$. $S$ was then removed and replaced in the startbox for a second, identical, trial. Ss were tested for 7 weeks, with five daily tests and 2 days of rest per week. The schedule of testing for the two groups is shown in Table 1 . The procedure was basically as follows: During Week 1, all Ss were tested with no drug. Then for three pairs of weeks, the two groups were alternately under drugged or nondrugged conditions, with the dosage $10 \mathrm{mg} / \mathrm{kg}$ for the first two pairs of weeks and increased to $50 \mathrm{mg} / \mathrm{kg}$ for the last pair of weeks. The replication at $10 \mathrm{mg} / \mathrm{kg}$ was because of some lingering uncertainty about the results of the first test.

$$
\text { DRUG PREPARATION }
$$

\section{AND ADMINISTRATION}

In order to facilitate drug administration, the rats were first placed on a diet of $30 \mathrm{~g}$ of standard rat chow per day, with feeding taking place at the time when the drug would later be administered. Weight was maintained by all Ss on this diet, but all were eager to eat at the scheduled time. Before testing, each $S$ was carefully weighed and the appropriate

Table 1

Dose (mg/kg) Sequence

\begin{tabular}{rrrrrrr}
\hline & & \multicolumn{7}{c}{$\begin{array}{c}\text { Week } \\
4\end{array}$} & 5 & 6 & 7 \\
0 & 10 & 0 & $\begin{array}{c}\text { Group } 1 \\
10\end{array}$ & 0 & 50 & 0 \\
0 & 0 & 10 & 0 & 10 & 0 & 50 \\
\hline
\end{tabular}


amount of the drug mixture was prepared. The dry crystalline powder (nitrazepam supplied gratis by Hoffman-La Roche, Inc., Nutley, N.J.) was mixed with unbleached white flour to facilitate the weighing. For the 10-mg dose, one part ("part" always refers to weight) nitrazepam was mixed with 999 parts flour, while for the $50-\mathrm{mg}$ dose it was one part drug and 99 parts flour. The drug-flour mixture was sifted and shaken up many times. Before a test, $\mathrm{S}$ was carefully weighed and enough of the mixture weighed out so that the appropriate amount of the drug was included. A rat weighing $150 \mathrm{~kg}$, for example, on a dose of $10 \mathrm{mg} / \mathrm{kg}$ would received $1,500 \mathrm{mg}$ of the $\mathrm{mix}(1.5 \mathrm{mg}$ nitrazepam and $1,498.5 \mathrm{mg}$ flour). The drug-flour dose was then matched with an equal weight of powdered rat chow and an equal weight of white refined sugar (sucrose). Then the weight of the entire mixture was matched by an equal weight of water and the whole thing reduced to a paste. For example, our rat above would finally get a paste containing $1.5 \mathrm{mg}$ nitrazepam, $1,498.5 \mathrm{mg}$ flour, $1,500 \mathrm{mg}$ rat chow, $1,500 \mathrm{mg}$ sugar, and $4,500 \mathrm{mg}$ water, for a total weight of $9 \mathrm{~g}$. The paste was placed in a glass coaster in S's cage $40 \mathrm{~min}$ prior to testing. It was always readily consumed, with the coaster "licked clean" long before $10 \mathrm{~min}$ had elapsed. Each $S$ thus received very close to the doses shown in Table 1. RESULTS

It can be seen at a glance that Table 2 shows no changes in alternation that can be ascribed to a specific effect of the drug on the hippocampus. For example, the totals for both test series at $10 \mathrm{mg} / \mathrm{kg}$ differ by merely $1.2 \%$ for the drug and placebo groups. While it might superficially appear that the $50 \mathrm{mg} / \mathrm{kg}$ dose was somewhat effective in reducing alternation, the difference was mainly due to two factors. First, the placebo control performance for that test just happened to be well above the overall mean. Second, one S alternated just once in five tests and is largely responsible for the low rate of $75 \%$ in that cell of the table. If this $S$ is excluded, alternation would average $83 \%$ with the $50 \mathrm{mg} / \mathrm{kg}$ dose, a rate within $4 \%$ of the overall placebo mean. Difference $t$ tests were computed for every conceivable comparison of tests, doses, and totals. By far the highest $t$ was the $1.8(\mathrm{df}=7)$ for the $50-\mathrm{mg}$ dose vs the placebo rate for that particular test. The $t$ is much lower when all placebo tests are combined. In no case was a difference found which was not well within what one would expect on the basis of chance variability. Thus, it seems clear that alternation was not reliably affected

Table 2

Spontaneous Alternation Rates After Drug or Placebo Treatments

\begin{tabular}{lcc}
\hline & Drugged & Placebo \\
\hline $\begin{array}{l}\text { Pretest } \\
10 \mathrm{mg} / \mathrm{kg}\end{array}$ & - & 83.8 \\
$\begin{array}{l}\text { Test 1) } \\
10 \mathrm{mg} / \mathrm{kg}\end{array}$ & 80.0 & 92.5 \\
$\begin{array}{l}\text { Test 2) } \\
\begin{array}{l}\text { Total, both } \\
10 \mathrm{mg} \text { tests }\end{array}\end{array}$ & 87.5 & 77.5 \\
$\begin{array}{l}50 \mathrm{mg} / \mathrm{kg} \\
\text { Total, all } \\
\text { drug doses }\end{array}$ & 83.8 & 85.0 \\
\hline
\end{tabular}

by the drug. Even with the 50-mg dose, alternation occurred at a rate reliably above a chance $50 \%(t=2.6$, $\mathrm{p}<.05$ ).

In a sense, it must be considered to be remarkable that alternation was apparently unaffected by nitrazepam. The reason is that even at the $10-\mathrm{mg}$ dose general changes in behavior were noted, while at $50 \mathrm{mg}$ these assumed an extreme form. That is, at the low dose some Ss were behaviorally "tranquilized," while at $50 \mathrm{mg}$ the term "stunned" might be more appropriate. Strangely, however, the emotional effects were highly individualistic. While most Ss appeared to be emotionally depressed, three actually exhibited unmistakable "rage" behavior. At the high dose many individuals staggered or stumbled, while some would not struggle to right themselves when placed upside down in the hand of the E. Under these conditions, a reduction in alternation, if it had occurred, would hardly have been an argument for specific effects of nitrazepam on hippocampal function. Despite these often rather dramatic side effects, not a single $S$ failed even once to run (or stagger) in the maze and, with the exclusion of one $S$, their alternation rates were well within the range expected for normal undrugged rats. DISCUSSION

On the basis of this evidence, one might tentatively conclude that nitrazepam has no specific effect of enhancing or depressing the contribution of the hippocampus to behavior, as measured by the present task. This would be difficult to believe if the results of Steiner \& Hummel (1968) were interpreted as indicating that nitrazepam blocks all sensory input to the hippocampus. In that study, however, the effect was demonstrated only with stimulation of the visual system. It has been shown conclusively that visual stimuli are not normally important cues for spontaneous alternation in the rat (Dember, 1958; Douglas, 1966). Alternation is guided primarily by vestibular cues, and our results thus suggest that vestibular input to the hippocampus is unimpaired by nitrazepam. Since both the function of the hippocampus and the phenomenon of spontaneous alternation are believed by many investigators to be basically inhibitory (see references), it would appear that at least one inhibitory brain mechanism is unimpaired by nitrazepam. Since emotional changes were readily observable even at the low dose, however, it would appear that the drug has a potent effect on some aspect of a basically excitatory or arousal system.

While our observations leave no room for doubt that nitrazepam has direct or indirect effects on emotionality, we cannot be sure that this implies an interference with amygdaloid function, however suggestive the data seem of this possibility. Our alternation data have no bearing on this possibility because amygdala lesions do not appear to affect the spontaneous alternation rate (Douglas et al, 1968).

Finally, the present findings could be added to a long list of variables which do not affect spontaneous alternation. The phenomenon remains specifically sensitive to drugs affecting the cholinergic system (Meyers \& Domino, 1964; Douglas \& Isaacson, 1966). Drugs like amphetamine (up to $2 \mathrm{mg} / \mathrm{kg}$ ) and chlorpromazine $(3 \mathrm{mg} / \mathrm{kg})$ have no effect at all (Adkins, Packwood, \& Marshall, 1969; Douglas, Pagano, Lovely, \& Peterson, 1970). Thus, it would appear that alternation mechanisms are, within limits, tangential to the arousal mechanisms which are changed so radically. by amphetamine, chlorpromazine, and now nitrazepam.

While oral drug administration is superior to injections for many purposes, the reader should be warned that our easy success with nitrazepam was not matched in an attempted scopolamine study. Oral scopolamine is apparently so unpleasant that a rat would rather starve than eat food contaminated with it in a reasonable dose.

ADKINS, J., PACKWOOD, J. W., \& MARSHALL, G. L., JR. Spontaneous alternation and D-amphetamine. Psychonomic Science, 1969, 17, 167-168. DEMBER, W. N. Stimulus altemation in peripherally blinded rats. Canadian Journal of Psychology, 1958, 12, 219-221.

DOUGLAS, R. J. Cues for spontaneous alternation. Joumal of Comparative \& Physiological Psychology, 1966, 62, 171-183.

DOUGLAS, R. J., \& ISAACSON, R. L. Hippocampal lesions and activity. Psychonomic Science, 1964, 1, 187-188.

DOUGLAS, R. J.. \& ISAACSON, R. L. Spontaneous alternation and scopolamine. Psychonomic Science, $1966,4,283-284$ 
DOUGLAS, R. J., KOWAL, D.. \& CLARK, G. Spontaneous alternation and the brain. Paper read at Western Psychological Association meeting, San Diego, 1968.

DOUGLAS, R. J., PAGANO, R. R., Proactive ECS effects the adrenal system and the hippocampus. Proceedings, 78 th Annual Convention, APA, 1970, 221-222.

DOUGLAS, R. J., \& PETERSON, J. J. Is it true what they say about two stage hippocampal lesions? Paper read at Western Psychological Assoeiation meeting, Vancouver, B.C., 1969.

DOUGLAS, R. J., \& RAPHELSON, A. C. Spontaneous alternation and septal lesions. Journal of Comparative \& Physiological Psychology, 1966, 62, 320-322.
MEYERS, B., \& DOMINO, E. F. The effect of cholinergic blocking drugs on spontaneous alternation in rats. Archives of International Pharmacodynamics, $1964,150,525-529$.

MORILLO, A. Effects of benzodiazepines upon amygdala and hippocampus of the cat. International Journal of Neuropharmacology, 1962, 1, 353.

RANDALL, L. O., \& SCHALLEK, W. Pharmacological activity of certain benzodiazepines. In D. H. Efron (Ed. in Chief), Psychopharmacology. A review of progress 1957-1967. Washington, D.C: Public Health Service Publications, 1968, 153-184.

ROBERTS, W. W., DEMBER, W. N., \& BRODWICK, $M$. Alternation and exploration in rats with hippocampal lesions. Journal of Comparative \&
Physiological Psychology, 1962, 55, 695-700.

SCHALLEK, W., ZABRANSKY, F., \& KUEHN, A. Effects of benzodiazepines on central nervous system of cat Archives of International Pharmacodynamics, 1964, 149, 467.

SCHALLEK, W., THOMAS, J., KUEHN, A., \& ZABRANSKY, F. Effects of Mogadon on responses to stimulation of sciatic nerve, amygdala and hypothalamus of cat. International Journal of Neuropharmacology, 1968, 7, 61-69.

STEINER, F. A., \& HUMMEL, P. Effects of nitrazepam and phenobarbital on hippocampal and lateral geniculate neurones in the cat. International Journal of Neuropharmacology, 1968, 7, 61-69. 